\title{
POLA KALIMAT TUNGGAL PADA TEKS DESKRIPSI SISWA KELAS VII SMP NEGERI I PONDOK KELAPA BENGKULU TENGAH TAHUN AJARAN 2016/2017
}

\author{
Lilis Suyanti ${ }^{1}$, Supadi ${ }^{2}$, dan Marina Siti Sugiyati ${ }^{3}$ \\ ${ }^{1,2,3}$ Program Studi Pendidikan Bahasa dan Sastra Indonesia \\ Jurusan Pendidikan Bahasa dan Seni \\ FKIP Universitas Bengkulu \\ lilissuyanti875@yahoo.com
}

\begin{abstract}
Abstrak
Tujuan penelitian ini adalah untuk mendeskripsikan pola, fungsi, kategori dan peran unsurunsur kalimat tunggal dalam teks deskripsi siswa kelas VII SMP Negeri 1 Pondok Kelapa Bengkulu Tengah tahun ajaran 2016-2017. Metode yang digunakan yaitu metode deskriptif kualitatif. Data dan sumber data dalam penelitian ini berupa kalimat-kalimat tunggal pada teks deskripsi siswa kelas VII SMP N 1 Pondok Kelapa Bengkulu Tengah tahun ajaran 2016/2017. Teknik analisis data dalam penelitian ini menggunakan teknik permutasi dan teknik parafrase. Hasil penelitian ditemukan pola-pola kalimat tunggal sebagai berikut, S-P, S-P-O, S-P-Pel, S-P-Ket, S-P-O-Ket, S-P-O-Pel, S-Ket-P-O, Ket-S-P, Ket-S-P-O, Ket-S-P-Pel, Ket-SP-O-Pel, Ket-S-P-O-Ket, S-Ket-P-Pel, S-Ket-P-Ket, Ket-S-Ket-P-Pel, S-P-Pel-Ket, S-Ket-P, S-KetKet, Ket-P-O-Pel, Ket-P-Pel-Ket, Ket-S. Analisis kalimat berdasarkan fungsi ditemukan fungsifungsi kalimat sebagai berikut: S, P, O, Ket, Pel. Analisis kalimat berdasarkan ketegori ditemukan: Fungsi $S$ berkategori nomina, dan frase nomina. Fungsi $P$ berkategori nomina, frase nomina, verba, frase verba, frase adjektifa, dan frase numeralia. fungsi O berkategori nomina, frase nomina dan frase numeralia. Fungsi Pel berkategori nomina, dan frase nomina. Fungsi Ket berkategori frase preposisi. Analisis kalimat berdasarkan peran ditemukan sebagai berikut: Fungsi $S$ berperan sebagai dikenal, pengalam, terjumlah, pelaku, pemeroleh, dan tempat. fungsi $P$ berperan sebagai pengenal, keadaan, jumlah, perbuatan, kepemilikan, keberadaan, dan pemerolehan. Fungsi O berperan sebagai penderita, pemilik, jumlah, hasil, dan terjumlah. Fungsi Pel berperan sebagai penderita, pemilik, terjumlah, hasil, keadaan, dan alat. Fungsi Ket berperan sebagai cara, tempat, waktu, peserta, hasil, alat, sebab, dan keseringan.
\end{abstract}

\section{Kata Kunci: Pola Kalimat Bahasa Indonesia, Teks Deskripsi}

\begin{abstract}
The purpose of this study are to describe the pattern, function, category and the role of single sentence elements in the text description of students in class VII of SMP Negeri 1 Pondok Kelapa Bengkulu Tengah academic year 2016-2017. The method used is qualitative descriptive method. Data and data sources in this study are single sentences in the text description of students in class VII SMP N 1 Pondok Kelapa Bengkulu Tengah academic year 2016/2017. Data analysis technique in this research using permutation technique and paraphrase technique. The results of the research found the following single sentence patterns, S-P, S-P-O, S-P-Pel, S-P-Ket, S-P-O-Ket, S-P-O-Pel, S-Ket-P-O, Ket-S-P, Ket-S-P-O, Ket-S-P-Pel, Ket-S-P-O-Pel, Ket-S-P-O-Ket, S-Ket-P-Pel, S-Ket-P-Ket, Ket-S-Ket-P-Pel, S-P-PelKet, S-Ket-P , S-Ket-Ket, Ket-P-O-Pel, Ket-P-Pel-Ket, Ket-S. Sentence analysis based on function found sentence functions as follows: $S, P, O$, Ket, Pel. Sentence analysis based on
\end{abstract}


category is found: The function of $S$ are categorized as noun, and noun phrase. The $P$ functions are categorized nouns, noun phrases, verbs, verb phrases, adjective phrases, and numeralia phrases. The $\mathrm{O}$ function are categorized as noun, noun phrase and numeralia phrase. Pel functions are categorized nouns, and noun phrases. The function of Ket is categorized as prepositional phrase. The role-based sentence analysis are found as follows: The function $\mathrm{S}$ acts as a known, experienced, numbered, actor, gained, and place. Function $\mathrm{P}$ acts as an identifier, state, amount, deed, possession, existence, and acquisition. Function $O$ acts as a sufferer, owner, sum, result, and sum. The Pel function acts as the sufferer, owner, number, result, state, and tool. The function of Ket serves as a way, place, time, participant, result, tool, cause, and frequency.

\section{Keywords: Indonesian Sentence Pattern, Description Text}

\section{PENDAHULUAN}

Linguistik atau ilmu bahasa memiliki dua tataran, yaitu tataran fonologi dan tataran gramatika (tata bahasa). Tataran gramatika terbagi menjadi dua subbahasan yaitu morfologi dan sintaksis. Morfologi adalah bagian tata bahasa yang mempelajari seluk beluk kata. Sedangkan sintaksis mempelajari hubungan kata, frasa, klausa, kalimat dan wacana (Ramlan, 1987:21). Berdasarkan fungsi dan peran gramatikalnya ada enam tipe kalimat yang dapat dijadikan model pola kalimat dasar bahasa indonesia. Berdasarkan fungsi dan peran gramatikalnya ada enam tipe kalimat yang dapat dijadikan model pola kalimat dasar bahasa indonesia. Keenam tipe kalimat tersebut menurut Finoza (2013:30), yakni: Kalimat Dasar Tipe S-P, S-P-O, S-PPel, S-P-Ket, S-P-O-Pel, S-P-O-Ket. Keenam tipe kalimat dasar ini dapat memudahkan seseorang dalam memahami sebuah kalimat, dengan menemukan polapolannya. Sehubungan dengan pola kalimat (Verhaar, 1996; Putrayasa, 2007; Sumadi, 2009) menganalisis kalimat berdasarkan fungsi, kategori dan peran dilakukan pada kalimat dasar. Ketiga aspek yaitu fungsi, ktegori dan peran tersebut sebenarnya berbeda namun berkaitan. Istilah fungsi mengacu pada fungsi unsurunsur kalimat dalam sintaksis, yaitu keterkaitan struktural antara konstituen yang satu dengan konstituen yang lain dalam kalimat itu (Sumadi, 2009:201). Fungsi sintaksis artinya berkaitan dengan urutan kata atau frase dalam kalimat. Fungsi sintaksis utama dalam bahasa adalah predikat, subjek, objek, pelengkap, dan keterangan (Sumadi, 2009; Putrayasa 2007). Analisis kalimat berdasarkan kategori mengacu pada kategori frasa yang menduduki fungsi-fungsi sintaksis tersebut (Sumadi, 2009:201). Kalimat juga dianalisis berdasarkan peran. Analisis kalimat berdasarkan peran mengacu pada makna pengisi fungsional unsur-unsur kalimat. Verhaar (1996) mengatakan bahwa 'peran' adalah segi semantis dari peserta-peserta verba. Unsur-unsur ini berkaitan dengan makna gramatika/sintaksis.

Sebagai sarana pengungkapan pikiran yang utuh secara ketatabahasaan, satuan gramatik kalimat membawa peran penting dalam komunikasi. Melalui pola kalimat yang benar, komunikasi dapat terjalin dengan baik. Pesan yang ingin disampaikan penulis atau pembicara dapat tersampaikan dengan benar pula kepada pembaca atau pendengar.

Ramlan (2005:23), kalimat merupakan satuan gramatik yang dibatasi oleh jeda panjang yang disertai nada akhir turun naik. Sedangkan menurut Chaer (2007:240), kalimat adalah satuan sintaksis yang disusun dari konstituen dasar, yang biasanya berupa klausa, dilengkapi dengan konjungsi bila diperlukan, dan disertai 
dengan intonsi final.

Pada hakikatnya sebuah kalimat dapat ditelusuri pola-pola pembentukannya. Penguasaan pola kalimat akan memudahkan pemakai bahasa dalam membuat kalimat yang benar secara gramatikal. Selain itu, pola kalimat dapat menyederhanakan kalimat sehingga mudah dipahami orang lain (Widjono, 2005:144).

Dewasa ini pembelajaran mengarang menjadi salah satu aspek yang menuntut siswa untuk dapat mengekplorasi daya tulis mereka. Terlebih lagi dalam Kurikulum 2013 metode pembelajaran bahasa Indonesia difokuskan pada metode pembelajaran berbasis teks. Dalam kurikulum 2013 pembelajaran bahasa Indonesia dirancang sedemikian rupa dengan banyak melibatkan keempat keterampilan berbahasa, hingga tersebutlah pembelajaran berbasis teks.

Teks deskripsi berada dalam KD 4.3 K13 kelas VII hal ini menjadikan kedudukan teks deksripsi semestinya menjadi bahan acuan untuk melihat kemampuan anak pada tahap bahasa antara, yang nantinya diharapkan anak dapat menghadapi tuntutan menulis lebih kompleks dijenjang selanjutnya. Oleh sebab itu, penulis tertarik pada teks deskripsi karena teks ini banyak menuntut siswa untuk menulis, dan hal ini dilakukan pada tahap awal di kelas VII. Dari uraian di atas, dapat disimpulkan perlunya penelitian pola kalimat bahasa indonesia dan hubungannya dengan fungsi komunikasi.

\section{METODE}

Penelitian ini dilakukan dengan menggunakan metode kualitatif. Data penelitian diambil dari setting alamiah, yaitu karangan yang sesungguhnya yang ditulis oleh siswa kelas VII SMP N I Pondok Kelapa Bengkulu Tengah Tahun Ajaran 2016/2017. Data dalam penelitian ini berupa data lunak, yaitu kalimat-kalimat yang terdapat dalam karangan siswa berupa teks deskripsi.

Teknik yang digunakan untuk mengumpulkan data dalam penelitian ini adalah teknik dokumentasi dan teknik catat.Teknik dokumentasi dilakukan dengan cara pengumpulan data berupa teks deskripsi siswa kelas VII SMP Negeri 1 Bengkulu Tengah tahun ajaran 2016/2017 sebagai dokumen dalam penelitian. Teknik catat dilakukan untuk pengumpulan kalimat-kalimat tunggal yang terdapat pada teks deskripsi siswa kelas VII SMP N 1 Pondok Kelapa Bengkulu Tengah tahun ajaran 2016/2017 di kartu data yang telah disiapkan.

Data yang telah diklasifikasikan tersebut akan dianalisis dengan menggunakan metode distribusional. Metode distribusional terdiri dari satu teknik dasar dan enam teknik lanjutan (Sudaryanto, 1982:13-14). Tidak semua teknik tersebut digunakan dalam penelitian ini, melainkan hanya beberapa teknik saja dengan disesuaikan pada kebutuhan dalam analisis data. Dari keenam teknik lanjutan tersebut, terdapat dua teknik yang digunakan dalam analisis data yaitu teknik permutasi dan parafrase.

Teknik permutasi atau teknik balik adalah teknik pertukaran letak unsurunsur kalimat dalam batasan-batasan tertentu. Teknik permutasi dilakukan dengan cara mengubah letak unsur kalimat untuk dibandingkan dengan kalimat sebelumnya. Meskipun melakukan perubahan letak unsur kalimat, penggunaan teknik permutasi ini tidak mengubah makna kalimat tersebut (Sudaryanto, 1993:16).

Teknik parafrase atau teknik ubah ujud yaitu penggunaan teknik ubah ujud yang selalu mengakibatkan berubahnya wujud salah satu atau beberapa unsur satuan lingual yang bersangkutan.

Setelah melakukan analisis data, tahap terakhir penelitian ini yaitu 
penarikan kesimpulan terhadap data yang sudah dianalisis.

\section{HASIL DAN PEMBAHASAN}

\section{Pola kalimat tunggal bahasa indonesia yang ditemukan dalam teks deskripsi siswa kelas VII SMPN I Pondok Kelapa Bengkulu Tengah.}

Sesuai dengan fokus penelitian ini, berikut disajikan hasil penelitian beserta pembahasannya. Sajian hasil penelitian beserta pembahasannya itu meliputi (1) hasil penelitian dan tentang wujud pola kalimat tunggal dalam teks deskripsi siswa kelas VII SMPN I Pondok Kelapa Bengkulu Tengah tahun ajaran 2016/2017, serta (2) hasil penelitian dan pembahasan tentang kategori dan peran dalam kalimat yang digunakan oleh siswa kelas VII SMPN I Pondok Kelapa Bengkulu Tengahtahun ajaran 2016/2017 dalam teks deskripsi. Hasil dan pembahasan selengkapnya disajikan berikut.

Penelitian tentang wujud pola kalimat bahasa Indonesia dalam teks deskripsi siswa kelas VII SMPN I Pondok Kelapa Bengkulu Tengah tahun ajaran 2016/2017 menghasilkan tiga hasil penelitian. Pertama, pola kalimat dalam teks deskripsi siswa kelas VII SMPN I Pondok Kelapa Bengkulu Tengah tahun ajaran 2016/2017 ada yang menggunakan pola kalimat tunggal dan ada yang menggunakan pola kalimat majemuk. Kedua kalimat dalam bahasa Indonesia dalam teks deskripsi siswa kelas VII SMPN I Pondok Kelapa Bengkulu Tengahtahun ajaran 2016/2017 dilihat dari kehadiran unsur intinya ada yang sudah lengkap dan ada tidak lengkap. Ketiga, kalimat sederhana dalam teks deskripsi siswa kelas VII SMPN I Pondok Kelapa Bengkulu Tengah bervariasi, yaitu berpola S-P, S-P-O, S-P-Pel, S-P-Ket, S-P-O-Ket, S-P-O-Pel, S-Ket-P-O, Ket-S-P, Ket-S-P-O, Ket-S-P-Pel, Ket-S-P-OPel, Ket-S-P-O-Ket, S-Ket-P-Pel, S-Ket-P-Ket, Ket-S-Ket-P-Pel, S-P-Pel-Ket, S-Ket-P, S-Ket-
Ket, Ket-P-O-Pel, Ket-P-Pel-Ket, Ket-S.

Berkaitan dengan hasil penelitian tersebut dapat dikemukakan pembahasan berikut. Terhadap temuan digunakannya kalimat berklausa dan tidak berklausa dalam karangan deskripsi siswa kelas VII SMPN I Pondok Kelapa Bengkulu Tengahtahun ajaran 2016/2017, jumlah kalimat berklausa yang didapatkan sebanyak 151 kalimat dari jumlah keseluruhan 280 kalimat dalam 32 karangan siswa kelas VII SMPN I Pondok Kelapa Bengkulu Tengah.

Meskipun dalam penelitian ini siswa ditugasi untuk mengarang teks deskripsi secara bebas, ternyata semua karangan yang dihasilkan siswa berupa teks deskripsi ekspositoris yang berisi deskripsi secara rinci tentang sesuatu. (Keraf, 1985:94) menyebutkan bahwa teks deskripsi ekspositoris adalah jenis teks deskripsi yang bertujuan untuk memberikan informasi secara rinci kepada pembaca. Jadi tujuan dari pemaparan ini adalah untuk menyampaikan bahwa karangan deskripsi sangat bertalian dengan pelukisan kesan panca indra terhadap suatu objek.

\section{Fungsi kategori dan peran unsur-unsur kalimat tunggal yang ditemukan dalam teks deskripsi siswa kelas VII SMPN I Pondok Kelapa Bengkulu Tengah.}

Berdasarkan pola-pola kalimat yang ditemukan dalam dalam teks deskripsi siswa kelas VII SMPN I Pondok Kelapa Bengkulu Tengah tahun ajaran 2016/2017, maka dapat diuraikan sebagai berikut: S-P, S-P-O, S-P-Pel, S-P-Ket, S-P-O-Ket, S-P-OPel, S-Ket-P-O, Ket-S-P, Ket-S-P-O, Ket-S-PPel, Ket-S-P-O-Pel, Ket-S-P-O-Ket, S-Ket-PPel, S-Ket-P-Ket, Ket-S-Ket-P-Pel, S-P-PelKet, S-Ket-P, S-Ket-Ket, Ket-P-O-Pel, Ket-PPel-Ket, Ket-S. 
PENUTUP

\section{Kesimpulan}

Berdasarkan paparan data, hasil penelitian dalam karangan deskripsi siswa kelas VII SMPN I Pondok Kelapa Bengkulu Tengah Tahun .Ajaran 2016/2017, dapat disimpulkan sebagai berikut:

1) Penulis menemukan berbagai bentuk kalimat tunggal dalam karangan deskripsi siswa kelas VII SMPN I Pondok Kelapa Bengkulu Tengah Tahun Ajaran 2016/2017. Kalimat tunggal yang diperoleh sebanyak 151 kalimat. Kalimat yang dominan digunakan adalah kalimat tunggal berpola S-P.

2) Fungsi-fungsi yang menduduki unsurunsur kalimat di isi dengan kategori dan peran. Fungsi, kategori dan peran saling berhubungan. Dari hasil pembahasan ditemukan bahwa analisis kalimat berdasarkan fungsi, ketegori dan peran ditemukan: (1) fungsi $S$ berkategori nomina, dan frase nomina, (2) fungsi $P$ berkategori nomina, frase nomina, verba, frase verba, frase adjektifa, dan frase numeralia (3) fungsi $O$ berkategori nomina, frase nomina dan frase numeralia, (4) fungsi Pel berkategori nomina, dan frase nomina, (5) fungsi Ket berkategori frase preposisi. Berdasarkan peran (1) fungsi $S$ berperan sebagai dikenal, pengalam, terjumlah, pelaku, pemeroleh, dan tempat, (2) fungsi $P$ berperan sebagai pengenal, keadaan, jumlah, perbuatan, kepemilikan, keberadaan, dan pemerolehan, (3) fungsi $O$ berperan sebagai penderita, pemilik, jumlah, hasil, dan terjumlah, (4) fungsi Pel berperan sebagai penderita, pemilik, terjumlah, hasil, keadaan, dan alat (5) fungsi Ket berperan sebagai cara, tempat, waktu, peserta, hasil, alat, sebab, dan keseringan.
Saran

Berdasarkan kesimpulan, maka dapat diketahui saran dalam penelitain ini yaitu sebagai berikut:

1) Penelitian ini diharapkan dapat dijadikan sebagai tambahan wawasan terhadap ilmu bahasa terutama dibidang sintaksis. Selain itu, penelitian ini juga dapat dijadikan sebagai contoh dalam analisis kalimat berdasarkan fungsi, kategori, dan peran dalam suatu kalimat.

2) Untuk pendidik diharapkan dapat membantu peserta didik di sekolah, khususnya dalam menggunakan kalimat tulis pada kegiatan yang menuntut keterampilan menulis siswa.

3) Diharapakan hasil penelitian ini dapat dijadikan bahan pertimbangan dalam memperbaiki keterampilan menulis bagi siswa SMP di kota bengkulu.

4) Bagi peneliti selanjutnya di harapkan hasil penelitian ini dapat dilanjutkan kembali pada teks lainnya.

\section{DAFTAR PUSTAKA}

Chaer, Abdul. 2007. Linguistik Umum. Jakarta: Rineka Cipta.

Finoza, Lamuddin. 2013. Komposisi Bahasa Indonesia. Jakarta: Diksi Insan Mulia.

Putrayasa. 2007. Analisis Kalimat (Fungsi, Kategori dan Peran). Bandung: RefikaAditama.

Ramlan, M. 1987. Ilmu Bahasa Indonesia Sintaksis. Yogyakarta: C.V. Karyono.

2005. Sintaksis. Yogyakarta: C.V. Karyono.

Sudaryanto 1982. Metode Linguistik: Kedudukannya Aneka Jenisnya, dan FaktorPenentuWujudnya. 
Yogyakarta: Fakultas Sastra dan Kebudayaan University Gadjah MadaBulaksumur.

1993. Metode Linguistik. Yogyakarta: Gajah Mada University Press.

Sumadi. 2009. kalimat bahasa indonesia dalam wacana tulis siswa kelas VI
SD. Jurnal Bahasa, Seni dan Pengajarannya , 31.

Widjono. 2005. Bahasa Indonesia Mata Kuliah Pengembangan Kepribadian di PerguruanTinggi. Jakarta: PT Grasindo.

Verhaar. 2012. Asas-Asas Linguistik Umum. Yogyakarta: Gadjah Mada University Pres. 